CIC. Cuadernos de Información y Comunicación ISSN: 1135-7791

http://dx.doi.org/10.5209/CIYC.55973

\title{
Cartografías musicales de Madrid: Ciudad, música popular y nuevas tecnologías digitales ${ }^{1}$
}

\author{
Josep Pedro ${ }^{2}$
}

Enviado: 13-marzo-2017 / Aceptado: 28- marzo-2017

Resumen. El objetivo de este artículo es presentar y discutir una serie de cartografías musicales de la escena madrileña, que permiten visualizar su localización geográfica y comprender la naturaleza heterogénea de los lugares que la conforman. Se trata de seis mapas digitales online, definidos por la naturaleza, historia e identidad de los diversos lugares, y su elaboración forma parte una investigación etnográfica y analítica de la escena de blues en Madrid. No obstante, los mapas trascienden sus límites y muestran el solapamiento de distintos géneros musicales en lugares comunes de la escena urbana. Vinculado a cuestiones de antropología, geografía, identidad, memoria y nuevas tecnologías, el planteamiento de este tratamiento cartográfico de la escena permite aproximarnos al objeto desde una perspectiva diacrónica y sincrónica, que contribuye a su estudio musical, cultural y comunicativo.

Palabras clave: cartografía musical; mapa; Madrid; música popular; cultura urbana.

\section{[en] Musical Cartographies of Madrid: City, Popular Music and New Digital Technologies}

\begin{abstract}
The objective of this paper is to describe and to discuss a series of musical mappings of Madrid scenes, that allow us to visualize its geografical location as well as to understand the heterogeneous nature of the places which form it. We present six digital online maps defined by the nature, the history and the identity of blues scenes in Madrid. These maps, however, do transcend their boundaries to show the mixture of different musical styles in common places of urban music. the focus of this paper is linked with anthropological, geographical and identity and memory elements and new technologies, allowing us study our subject either from a diachronical and a synchronical perspective, which enriches its musical, cultural and communicative analysis.
\end{abstract}

Keywords: musical mapping; maps; Madrid; popular musical; urban culture.

Sumario. 1. Introducción. 2. Cartografiando la escena musical madrileña: miradas a la cultura urbana desde la perspectiva del blues. 2.1. Lugares de blues. 2.2. Lugares de jazz y blues. 2.3. Lugares de soul/ funk. 2.4. Lugares de varios géneros. 2.5. Blues de Taberna. 2.6. Madrid en vivo desde la escena de blues. 3. Conclusiones. 4. Bibliografía.

Cómo citar: Pedro, J. (2017). Cartografías musicales de Madrid: Ciudad, música popular y nuevas tecnologías digitales, en CIC. Cuadernos de Información y Comunicación 22, 169-185.

\footnotetext{
1 Este artículo se ha escrito al amparo de un contrato predoctoral de Formación de Profesorado Universitario (FPU), financiado por el Ministerio de Educación, Cultura y Deporte.

2 Universidad Complutense de Madrid.

Email: jpedro@ucm.es
} 


\section{Introducción}

Definida y materializada en distintas formas, la idea de cartografiar o mapear un territorio o un ámbito de estudios ha sido ampliamente utilizada en la tradición de las ciencias sociales y las humanidades. En los estudios sobre comunicación, Jesús Martín-Barbero ha empleado la noción de cartografía en un sentido muy amplio, llegando a describir su carrera académica -su "oficio"- desde los años 1970 como "un artesano ejercicio de cartografía" (2002: 10). Frente a las críticas a la fijación del mapa -a la necesaria reducción y deformación del objeto y de la realidad que implica la representación cartográfica-, Barbero ha defendido que la cartografía puede "construir imágenes de las relaciones y los entrelazamientos" y que su práctica puede contribuir a "abrir las ciencias sociales siguiendo y desbordando" rumbos previamente trazados (Ibíd.: 14).

Otros autores de reconocido prestigio como Umberto Eco y Lev Manovich también se han referido a la necesidad, utilidad y, al mismo tiempo, dificultad de generar mapas operativos sobre las transformaciones culturales y comunicativas. Ante la emergencia de culturas "subalternas", Eco (1985: 189) señaló que "lo que parece indispensable, con anterioridad a los tests de recepción, es un mapa geográfico de estas culturas y de los diversos sistemas de reglas y subreglas que ellas siguen", si bien la definición variable de "cultura subalterna" y el conocimiento incompleto de la cultura de masas dificultaba tal tarea. Por su parte, Lev Manovich emprendió su estudio sobre "el lenguaje de los nuevos medios de comunicación" desde la voluntad de describir y comprender las lógicas que lo guían, de desentrañar los "códigos semióticos de los medios informáticos" (2005: 50). Para ello, distinguiendo entre método y organización, elaboró una "cartografía de los nuevos medios" -concebida como un "mapa" metafórico, un instrumento de orientación ante las profundas transformaciones que han afectado a los medios de comunicación.

El desarrollo de las cartografías musicales que presento en este artículo se sitúa en la intersección entre la tradición etnográfica, los estudios de música popular y los usos académicos de las nuevas tecnologías de la comunicación. Se trata de seis mapas digitales online de la escena musical madrileña, definidos por la historia e identidad de los diversos locales de música en directo, que permiten visualizar su localización geográfica y comprender la naturaleza heterogénea de los lugares que la conforman. ${ }^{3}$ Este ejercicio cartográfico forma parte de una investigación en curso sobre las escenas de blues en Austin, Texas y Madrid, de manera que los mapas han sido elaborados desde esa perspectiva, desde la interpretación del blues en vivo. No obstante, debido a la distinta naturaleza y programación de los locales en los que, con frecuencia variable, se interpreta música blues, los mapas representan pero también trascienden la escena de blues, apuntando hacia el solapamiento y la potencial interrelación de distintos géneros musicales en lugares comunes de la escena urbana.

Definimos las "escenas musicales" como contextos espacio-temporales glocales de experiencias musicales, formados activa y cotidianamente por diversos participantes con roles y grados de implicación diversos (músicos, aficionados, empresarios, promotores, prensa...). Asumimos una noción flexible del concepto, puesto que reconocemos que en el interior de una escena musical urbana caben distintas escenas o (sub)escenas interrelacionadas y definidas diferenciadamente según género o estilo. 
La elaboración de mapas ha sido una constante en la tradición etnográfica, tanto en su desarrollo antropológico "clásico", como en su vertiente y aplicación contemporánea. Así, cabe señalar que la etnografía ha jugado un papel fundamental en la tradición de los estudios de etnomusicología y música popular, donde ha permitido investigar prácticas, discursos y valores de diversas culturas, tanto exóticas y lejanas (Blacking, 1995) como aparentemente familiares y cercanas (Grazian, 2003). Consideremos, en primer lugar, el caso del célebre antropólogo Bronislaw Malinowski. En su clásico estudio sobre los indígenas de los archipiélagos de Nueva Guinea, Malinowski empleó la cartografía para proporcionar representaciones visuales y conceptuales sobre el mundo exótico que estaba descubriendo y, además, distinguió entre el tratamiento científico y el de sentido común afirmando que "el objeto de la preparación científica es proveer al investigador empírico de una especie de mapa mental que le permita orientarse y seguir su camino" (1986: 30). En este sentido, Malinowski concibió los mapas como producciones textuales propias de la investigación y la escritura etnográfica (empleó cinco mapas geográficos con distintas variables en su obra más reconocida), y también como un mecanismo de orientación práctica y mental a la hora de hacer la etnografía. ${ }^{4}$

En el ámbito de la etnomusicología y la música popular, el desarrollo de mapas o cartografías musicales como herramientas de investigación y guías prácticas para investigadores y participantes sigue una tradición de estudios interesados en la representación y el análisis de las relaciones entre músicas, lugares y ciudades. Entre ellos cabe destacar: la aplicación de la cartografía musical a la investigación sobre la distribución geográfica de la música en distintas regiones del mundo (Nettl, 1960); el uso de mapas etnográficos para representar la localización espacial de la escena musical estudiada, así como la organización de la ciudad en la que se inserta (Lashua, Cohen y Schofield, 2010; Shank, 1994); y las investigaciones específicas sobre el proceso de cartografía musical y su aplicación a distintos casos de estudio (Roberts, 2012; Finn y Luckinbeal, 2009).

En los últimos años, el desarrollo, popularización y, en cierta medida, democratización de las tecnologías digitales ha contribuido decisivamente al auge de múltiples cartografías musicales online. Existen mapas interactivos sobre los géneros y subgéneros musicales, como "Music Map"; mapamundis musicales como "Musical Map: Cities of the World", que ordenan y permiten reproducir las canciones más escuchadas a través de la aplicación Spotify en las principales ciudades del mundo; y proyectos de investigación como "Mapping Popular Music in Dublin" (Dublin City University), centrados en "mapear la experiencia de la música popular" desde el punto de vista de los participantes de la escena y con una clara orientación al turismo y la industria local. ${ }^{5}$ En lo que respecta a las escenas musicales de Austin y Madrid, el geógrafo Eliot Tretter (2012; O'Meara y Tretter, 2013) ha empleado la cartografía de manera sistemática en sus estudios sobre la organización urbana de Austin, y la emisora radiofónica KUT ha creado un mapa musical ("Austin Music Map"), todavía en una fase de desarrollo temprana, en el que invita a los aficionados

Esta doble concepción del mapa remite a la doble vertiente de la etnografía: la realización práctica de un tipo de investigación cualitativa (hacer etnografía) y la creación de un determinado tipo de texto (escribir etnografía), construido a partir de descripciones sobre lugares, participantes y experiencias vividas.

5 Los mapas online citados pueden consultarse en los siguientes enlaces: www.musicmap.info; https://spotifymaps.carto.com/u/eliotvb/viz/971d1556-0959-11e5-b1a4-0e9d821ea90d/public_map; https://mappingpopularmusicindublin.wordpress.com/mapping-popular-music-in-dublin/ 
a etiquetar los lugares en los que han vivido experiencias musicales memorables. ${ }^{6}$ Por otra parte, la investigadora Vanessa Ceia ha desarrollado un proyecto cartográfico sobre el fenómeno de la "Movida madrileña", que propone recrearlo a través de las tecnologías digitales, visualizar las redes creativas y sus centros culturales, y crear un archivo de documentación público. ${ }^{7}$ Asimismo, el periódico Huffinton Post ha ampliado el mapa turístico elaborado por Metro Madrid incluyendo en él una selección de "canciones que mencionan sus rincones" (Santos, 2015).

Insertas en esta tradición, las cartografías musicales de la escena de blues en Madrid resultan novedosas y únicas porque emplean la precisa tecnología de Google My Maps (2007) para aproximar al lector al territorio de la escena y, sobre todo, porque abordan el fenómeno de la música en directo desde una perspectiva inclusiva en la que el blues -género que está en la raíz del desarrollo de la música popular contemporánea- actúa como punto de partida y exploración primario. El uso de la cartografía digital como herramienta etnográfica resulta especialmente útil en etnografías multi-situadas contemporáneas que, como la presente, investigan fenómenos culturales e interacciones presenciales en su desarrollo cotidiano, tratando de representar-de mapear- la complejidad de su sistema particular (Marcus, 1995: 100). En este caso, la cartografía musical tiene como objetivo el reconocimiento revelador de una realidad artística, sociocultural y urbana muy próxima geográficamente, pero que en buena medida todavía está por descubrir a nivel académico y social.

\section{Cartografiando la escena musical madrileña: miradas a la cultura urbana desde la perspectiva del blues}

Los mapas de la escena madrileña han sido elaborados a partir de la selección y clasificación de los lugares de interacción musical en los que se interpreta música blues. Además de locales de música en vivo, también hemos contabilizado una serie de lugares significativos para la escena en tanto construcción colectiva interconectada con instituciones y negocios de distinta naturaleza. Entre ellos incluimos sedes de entidades y asociaciones -como el Círculo de Bellas Artes (1880) y La Noche en Vivo (2001), cuyo archivo online de salas ha resultado útil para la recogida de datos; escuelas de música y baile - como la Escuela de Blues de Madrid (2011) y Big Mama Swing (2012), respectivamente; tiendas de música -como Leturiaga (1963) y Delia Records (2014); estudios de grabación -como Enfase (1999); y festivales de música.

A través de la etnografía, la documentación y la operación cartográfica hemos considerado tanto aquellos lugares activos en los que se celebran actuaciones, como aquellos inactivos que permanecen en la memoria de los participantes comprometidos y que han jugado un papel relevante en la construcción histórica de la escena musical. Por tanto, las cartografías realizadas son útiles tanto desde un punto de vista sincrónico (la actualidad de los lugares de la escena en un momento determinado) como diacrónico (su evolución a lo largo del tiempo). En total hemos contabilizado 147 lugares, 99 activos y 48 inactivos. Junto al nombre de cada uno de ellos, en los mapas indicamos sus fechas de actividad (salvo en ciertos casos excepcionales en los que no ha sido posible).

Para abordar los objetivos específicos del tratamiento cartográfico de la escena, partí de un grupo de discusión online con músicos de blues experimentados y comprometidos con la escenas (Jorge "Flaco" Barral; Osi Martínez y J.b. Boni). Además,

http://austinmusicmap.com/about

https://mappingthemovida.com/about/ 
para completar la selección de los locales destacados y la recogida de los datos sobre fechas de actividad y definición estilística, he realizado 27 entrevistas online (a través del correo electrónico y de Facebook) y 5 entrevistas telefónicas. En la siguiente tabla pueden consultarse los datos sobre esta metodología específica, que fue complementada con la consulta de las hemerotecas de los periódicos $A B C$ y El País:

\begin{tabular}{|c|c|c|}
\hline \multicolumn{3}{|c|}{ Recogida de datos para la realización de cartografías musicales } \\
\hline Grupo de discusión & Entrevistas online & Entrevistas telefónicas \\
\hline $\begin{array}{l}\text { J.b. Boni; Jorge } \\
\text { "Flaco" Barral; Osi } \\
\text { Martinez (13/01/2015; } \\
\text { 10/02/2015; 12/02/ 2015; } \\
\text { 15/06/2015) }\end{array}$ & $\begin{array}{l}\text { David Menor }(14 / 01 / 2015) ; \text { Felix } \\
\text { Ramos }(21 / 01 / 2015 ; 14 / 09 / 2015) \text {; } \\
\text { "Phineas"Sánchez(27/01/2015); Pe- } \\
\text { dro "Hell Paso" }(01 / 02 / 2015) ; \text { Javier } \\
\text { Minguela }(01-02 / 02 / 2015) ; \text { Antonio } \\
\text { Gómez Bautista }(01-02 / 02 / 2015) \text {; } \\
\text { Carlos Arsuaga }(12 / 02 / 2015) ; \text { Steve } \\
\text { Jordan }(12 / 02 / 2015) ; \text { Tempo Club } \\
\text { (13/02/2015); Legend }(09 / 07 / 2015) ; \\
\text { El Plaza Jazz Club (22/01/2015); } \\
\text { El Junco (22/01/2015); Intruso Bar } \\
\text { (21/01/2015); Escuela de Blues } \\
\text { de Madrid (16/09/2015); Delto- } \\
\text { ya Music Bar (21/07/2015); Sala } \\
\text { Contraclub (27/07/2015); Alba- } \\
\text { tros Blues Festival (15/09/2015); } \\
\text { El 14 (10/07/2015); Fonjazz Club } \\
\text { (08/07/2015; 10/07/2015); Bruno } \\
\text { Corrales (16/09/2015); La Boca } \\
\text { Club (22/01/2015); Iván Iglesias } \\
\text { (22/06/2015); Fernando Roqueta } \\
\text { (26/07/2015; 16/09/2015); Miguel } \\
\text { Ángel Sutil (16/09/2015); Manuel } \\
\text { Varo "Delia" (16/09/2015); Café } \\
\text { del Infante (16/09/2015); Recoletos } \\
\text { Jazz Club (10/02/2017) }\end{array}$ & $\begin{array}{l}\text { “Jopo" Vallekas (14/01 } \\
/ 2015) ; \text { Café Populart }(21 \\
/ 01 / 2015) ; \text { Pirata's Rock } \\
\text { Wey }(03 / 02 / 2015) ; \text { Ramón } \\
\text { Farrán }(17 / 09 / 2015) \text {; Rom- } \\
\text { peolas Locales }(20 / 02 / 2017)\end{array}$ \\
\hline
\end{tabular}

Considerando la variedad de locales que programan música blues en Madrid, así como su diversa relación con distintos géneros, he clasificado los lugares seleccionados en distintas categorías: 1) lugares de blues, definidos y dedicados específicamente a este género; 2) lugares de blues y jazz; 3) lugares de soul/funk; 4) lugares de varios géneros (pop-rock, música afroamericana, flamenco...), en los que la programación de música en vivo es más relevante que el género en sí; y 5) blues de taberna, una categoría que responde más específicamente a un criterio espacial que, en cualquier caso, repercute en el tipo de música que puede interpretarse. He creado un mapa para cada categoría, indicando las fechas de actividad de los lugares, así como su grado de relación con el blues, $\mathrm{y}$ ofreciendo también contenidos multimedia de los lugares (fotografías, logos, textos, posters, vídeos musicales, etc.).

Además, partiendo de la selección de los locales activos, he elaborado un mapa general de actualidad que representa la extensión de la escena de blues y el estado 
actual del circuito madrileño de música en directo (dentro de los límites previstos). Centrado en la ciudad de Madrid y con extensiones importantes en localidades cercanas como Los Santos de la Humosa, Leganés, Alcorcón, Móstoles, o Talamanca del Jarama, entre otras, este mapa general permite visualizar la extensión colectiva y la integración de la escena de blues en el circuito musical de la ciudad, identificando también las principales continuidades y discontinuidades entre distintas escenas y espacios urbanos.

Para leer los mapas conviene conocer primero los códigos de color y forma que he empleado. Por una parte, el color de los iconos indica la actividad o inactividad de los locales: el verde indica que están activos y el rojo que están cerrados, mientras que el azul indica que son lugares activos vinculados a la escena musical (no clubs de música en vivo), y el amarillo la celebración de un festival. Por otra parte, la forma del icono representa el grado de vinculación e importancia de cada lugar con respecto al blues: la estrella indica una vinculación e importancia alta, el rombo intermedia-alta, el cuadrado intermedia-baja, y el círculo baja. De esta manera, haciendo uso de las posibilidades técnicas que ofrece la aplicación Google My Maps - destinada a que el usuario común (históricamente alejado de la producción cartográfica del poder hegemónico) pueda ser también productor de mapas- empleamos y desarrollamos el lenguaje digital a través de diversos colores y formas geométricas, que contribuyen decisivamente a la organización del mapa y que operan junto a sus principales "mecanismos de distorsión de la realidad": la escala, la proyección y la simbolización (De Sousa-Santos, 1991). Desde el punto de vista semiótico, los iconos representativos de los lugares son índices simbólicos; sitúan y etiquetan los lugares sobre el mapa-texto empleando formas convencionales, arbitrariamente definidas por el cartógrafo.

Debido a la naturaleza digital e interactiva de las cartografías musicales elaboradas, su visualización y comprensión es óptima a través de la navegación online. Por ello, para aprovechar al máximo sus informaciones y potencialidades, recomendamos su consulta en la web de creación propia Blues Vibe (Pedro, 2015). ${ }^{8}$ La publicación ordenada de los mapas en un post permite utilizar las cartografías musicales como una herramienta hipertextual e interactiva, a través de la cual explorar la localización de la escena y su distribución en distintas zonas de la ciudad, así como la propia música y el tipo de hibridación estilística que la ha definido. En su lugar, ofrecemos capturas-imágenes de los mapas creados, que inevitablemente los fijan de manera provisional (al modo del mapa tradicional), pero que indudablemente proporcionan una nueva mirada a la escena musical y a la cultura urbana, una representación contextual y colectiva, basada en la presencia física y tipología de los lugares de encuentro.

Creada en el año 2012 como página web (https://bluesvibe.com/) y comunidad de Facebook (https://www. facebook.com/BluesVibe/), Blues Vibe ha constituido una herramienta de investigación básica en la etnografía online y en la interrelación del investigador con las escenas estudiadas. En este caso, la publicación provisional de las cartografías musicales en un post público de Blues Vibe me ha permitido disponer de una plataforma online sobre la que poder categorizar, organizar y actualizar los datos recogidos hasta llegar a al estado presente de las cartografías. Temporalmente, la producción cartográfica ha tenido lugar entre los años 2015 y 2017. 


\subsection{Lugares de blues}

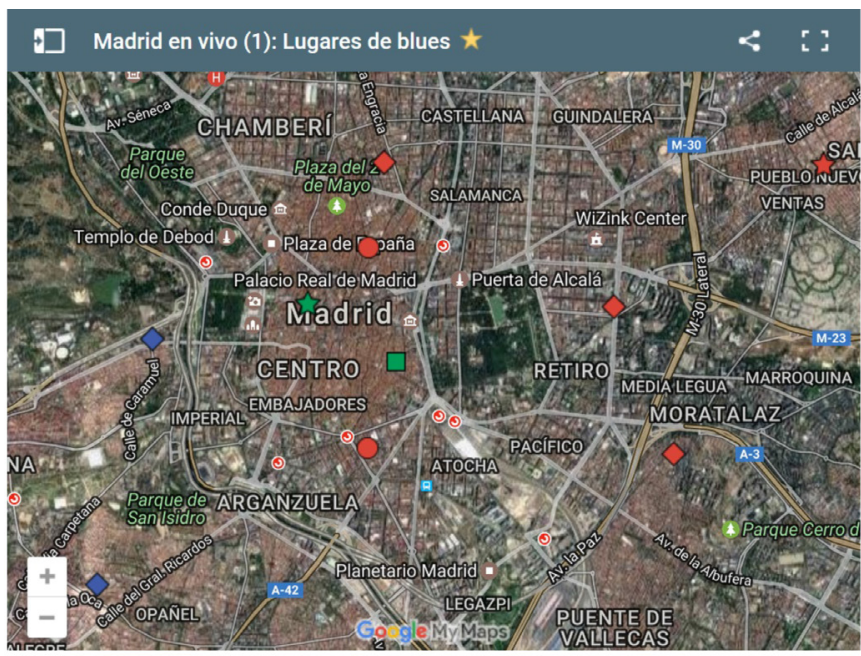

En el primer mapa, "Lugares de blues", hay 10 lugares contabilizados; 4 activos ( 2 iconos verdes y 2 azules) y 6 inactivos. La estrella verde del centro de Madrid representa La Coquette Blues Bar (1984), el club más emblemático, conocido como el "templo del blues"; y el cuadrado verde situado a su derecha (en el céntrico barrio de las letras) representa el local Blues Oscuro Casi Negro (2012), con una relevancia mucho menor, pero también definido por el blues -en su nombre alude a la negritud tradicional del género mediante una referencia a la película Azul oscuro casi negro (2006).

Sobre La Coquette, cabe remarcar que esa pequeña cueva subterránea, cargada de un aura de autenticidad que cautiva a numerosos espectadores, tanto especializados como casuales, ha jugado un papel fundamental en la construcción de la escena durante 33 años. De hecho, su apertura en los años 1980 contribuyó decisivamente a la "cristalización de la escena de blues", ese momento de consolidación y reivindicación del blues como género autónomo, en el que convergen músicos específicamente de blues, lugares de interacción definidos por el blues y públicos especializados.

Los rombos azules situados al oeste y suroeste del centro representan el estudio de grabación Enfase (1999), donde han grabado músicos de la escena de distintas generaciones; y la Escuela de Blues de Madrid (2011), dirigida por músicos de la escena de blues. Por su parte, los 6 iconos rojos representan otros locales de gran importancia en el desarrollo de la escena de blues: Beethoven Blues Bar (19962011), lugar de referencia, marcado con una estrella en la zona este (Pueblo Nuevo); Cotton Blues (1991-1994); Downtown (1993-2000); y Vapor Blues (1997-2001), todos ellos marcados con rombos en Vallecas, Retiro y Malasaña respectivamente; y también la celebración de dos festivales de blues ( 2 círculos rojos) que no han tenido continuidad, Festival Madrid Rock ' $n$ 'Blues (2012) -al sur del centro- y I Festival de Blues Intruso (2013) - con la colaboración de la Sociedad de Blues de Madrid, más al norte. 


\subsection{Lugares de jazz y blues}

En segundo lugar, vemos el mapa de lugares de blues y jazz -principalmente identificados con el jazz pero con espacio en su programación para el blues. Hemos contabilizado un total de 19 lugares (11 activos y 8 inactivos). El número de locales de música en vivo activos es superior al del mapa anterior: un total de 11, en los que sin embargo predominan círculos y cuadrados. Por su estrecha relación con el blues, destacamos el caso del Café Jazz Populart (1988-2016), marcado con un rombo rojo en el centro (barrio de las letras). Lugar emblemático de corte tradicional y orientación turística, el Populart fue reformado en 2015, iniciando una etapa de mayor eclecticismo y variedad de eventos que desembocó en su cierre en 2016. Así, su icono cartográfico (como el de otros clubs) pasó de verde a rojo durante la investigación. Actualmente, en el mismo espacio encontramos el local Blackbird Rock Bar (2016), definido estéticamente por el rock de los 1960 y 1970.

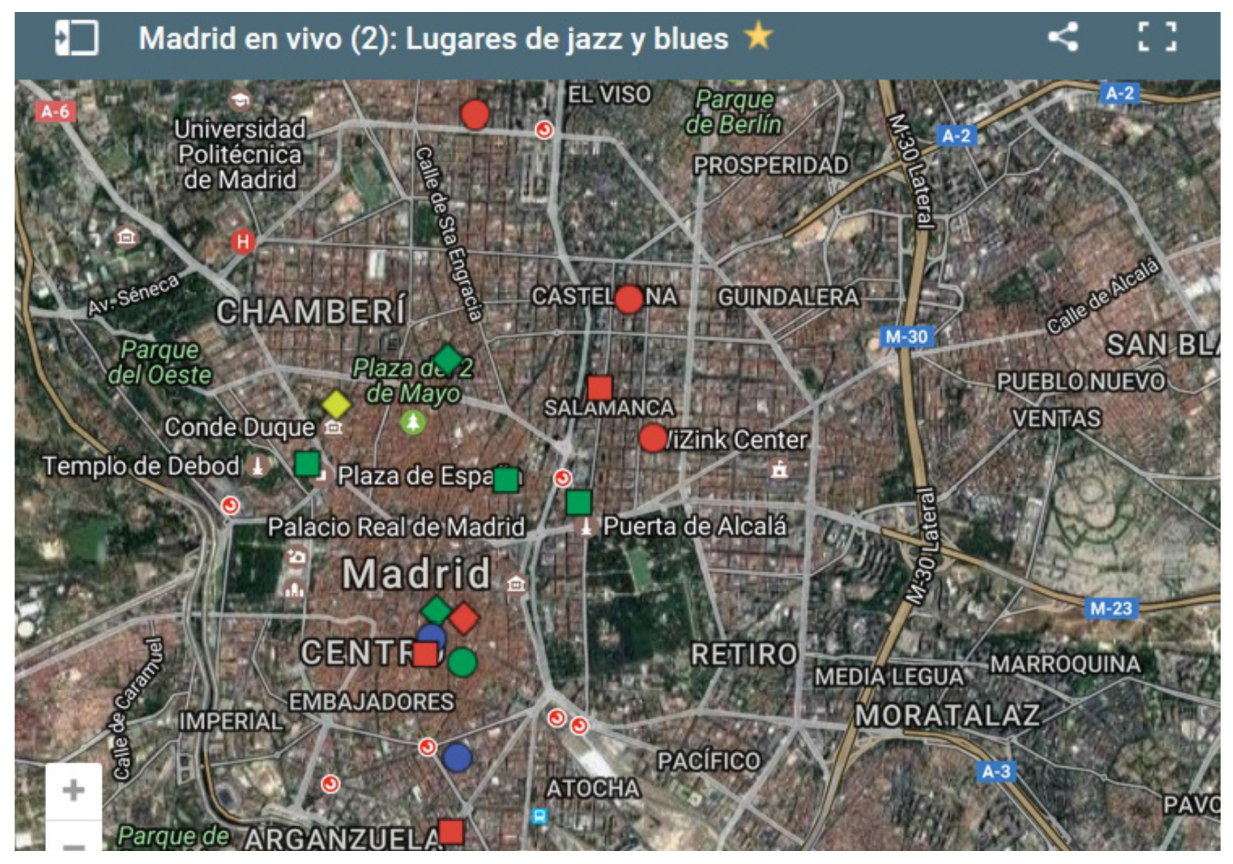

Otro lugar emblemático cuya transformación reciente sí ha sido exitosa es la Sala Clamores (1981). Bajo una nueva dirección, el histórico club de jazz se ha renovado en sintonía con su tradición, pero avanzando hacia una programación más ecléctica, con una importante presencia de artistas internacionales. La transformación interior del local ha jugado un papel fundamental, pues donde había dos espacios separados - uno para las mesas (normalmente reservadas) y otro al lado de la barra, mucho más alejado del escenario- ahora hay un continuum que favorece una experiencia musical más proclive al encuentro, al movimiento físico y al baile de los aficionados. 


\subsection{Lugares de soul/funk}

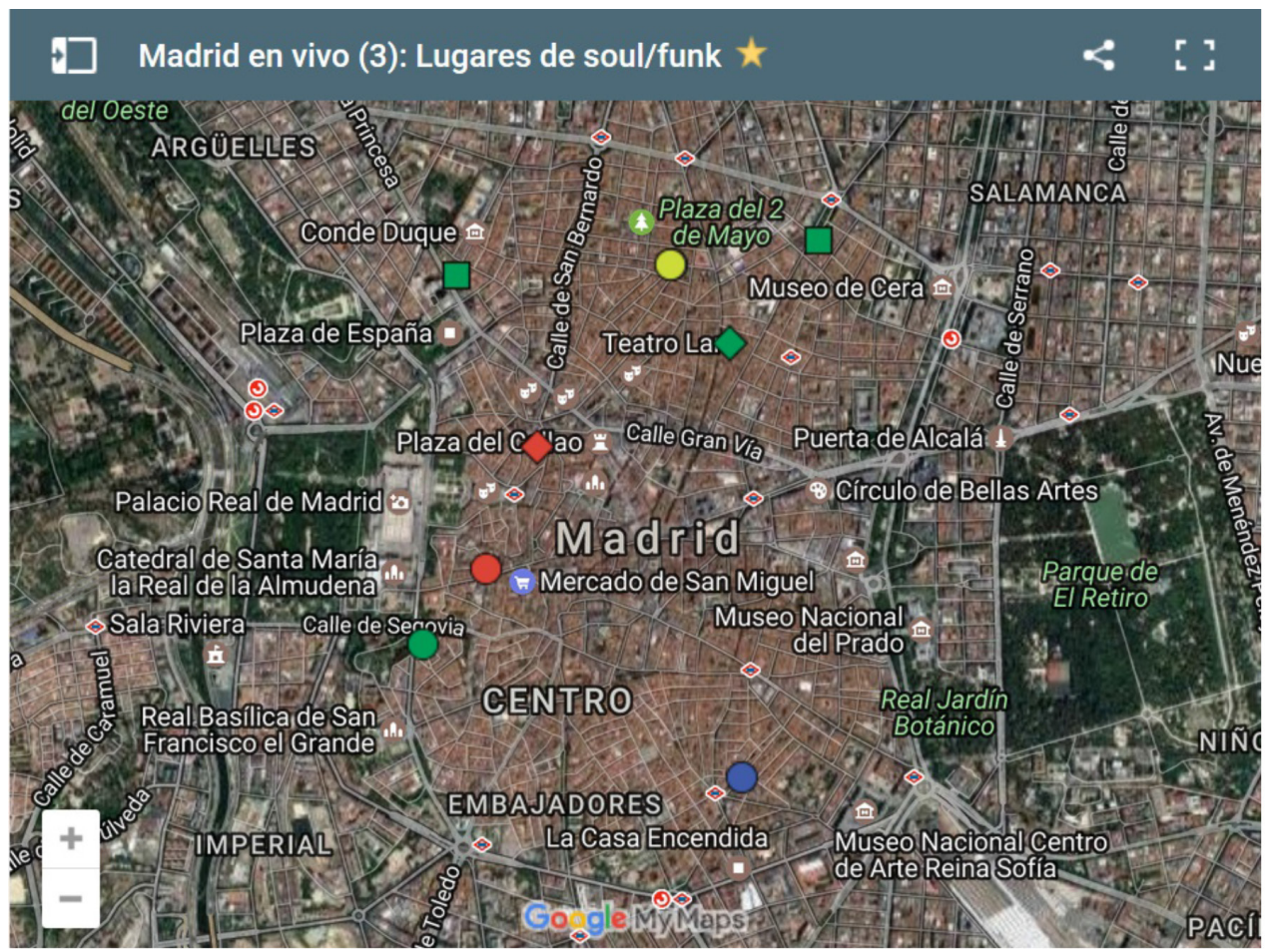

El mapa de lugares de soul y funk contiene 5 clubs activos de música en directo (iconos verdes): Moe Club (1998), representado por un rombo más al norte de lo que aparece en la captura (C/Alberto Alcocer, 32); el Tempo Club (2002), un cuadrado muy cerca de la Plaza de España; el Café Marula (2002), un círculo muy próximo a la calle Segovia; El Junco (2004), un cuadrado en el barrio de justica (al este de la Plaza del 2 de mayo); y El Intruso (2011), un rombo muy próximo al metro de Chueca.

Además, contabilizamos dos clubs-discotecas activas: The Maderfaker (1996), representado por un círculo azul en Malasaña y asociado también a la celebración del festival (círculo amarillo) Madrid es Negro (2010); y La Huelga (2010), un círculo azul en el barrio meridional de Lavapiés; así como un club de música en directo inactivo, Soul Station (2009-2013), marcado con un rombo rojo en la plaza de Santo Domingo. Entre ellos podemos destacar los casos del Moe Club (1998), que-situado en una zona septentrional con pocos locales- cuenta con una tradición consolidada de jam sessions de blues y conciertos de música afroamericana; y El Intruso (2011) local de programación heterogénea, también asociado a conciertos de blues y música afroamericana, donde se han celebrado (entre otros muchos eventos) fiestas de aniversario de la Sociedad de Blues de Madrid. 


\subsection{Lugares de varios géneros}

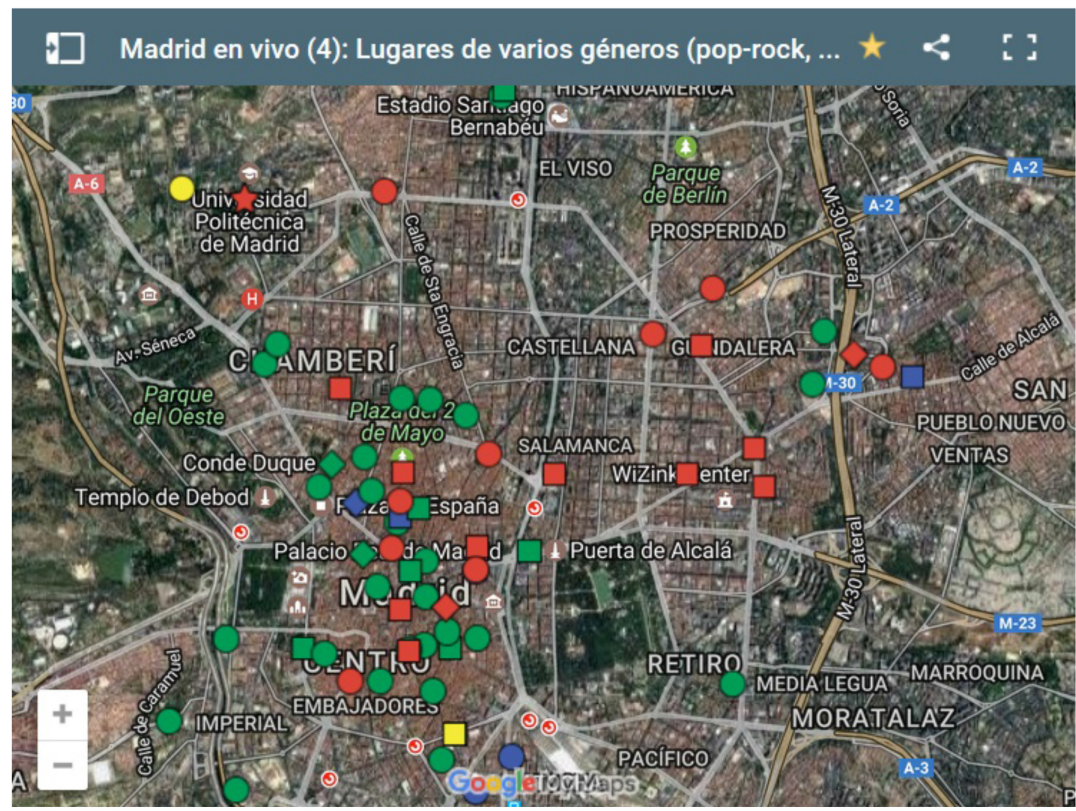

El mapa número cuatro, "Lugares de varios géneros", responde a una categoría estilística cuantitativamente más amplia y, consecuentemente, se aprecia un aumento significativo del número total de lugares contabilizados: 55 activos y 25 inactivos. Entre los lugares activos (iconos verdes) encontramos muchos representados a través de círculos y cuadrados, lo cual indica una menor relación con la música blues. No obstante, podemos destacar el caso del Café Berlín (2011/2016), representado por un rombo verde en la zona de Plaza de Santo Domingo y abierto originalmente a mediados de los años 1980 (en una localización muy próxima a la actual).

Estrechamente vinculado a la música afroamericana y el flamenco, entre otros géneros, su historia reciente es destacable en relación a las transformaciones urbanas del centro de Madrid, puesto que el club se ha visto obligado a trasladarse tras una operación inmobiliaria del magnate Harry Mohinani, en la que adquirió el edificio donde se encontraba el Café Berlín y también los dos bloques contiguos para construir un hotel de cuatro estrellas. Su caso, afortunadamente solventado sin excesivos problemas, apunta hacia el impacto de fenómenos urbanos como la especulación inmobiliaria y la gentrificación sobre la escena musical y la música en directo, recordando la incerteza, imprevisibilidad y dificultad que las caracterizan.

Entre los lugares inactivos destaca el emblemático Colegio Mayor San Juan Evangelista (1970-2014), representado por una estrella roja en la zona universitaria de la UCM (noroeste de la ciudad). Asociado musicalmente a una variedad de géneros (jazz, blues, flamenco, canción de autor, etc.), así como a la resistencia cultural e intelectual al Franquismo, el Colegio cerró en junio de 2014 y entró en una fase de degradación profunda. En noviembre de 2016, tras una disputa judicial entre la UCM y Unicaja y una larga lucha por parte de la Fundación del San Juan Evangelista, se alcanzó un acuerdo en el cual el Colegio volvía a ser de plena propiedad 
de la UCM. Recientemente, el documental Club de Reyes (Barrionuevo, 2016) ha rememorado su importancia histórica.

\subsection{Blues de Taberna}

En el mapa correspondiente a los lugares de "blues de taberna" -categoría creada para reconocer la particularidad de las experiencias musicales que tienen lugar en bares, bodegas y tabernas populares que tienden a servir comida- hemos contabilizado 17 lugares activos: 6 prácticamente en la zona centro de Madrid -la mayoría en la zona sur (barrios de Lavapiés, La Latina e Imperial), y 9 en barrios y localidades más periféricas (la mayoría no visibles en la captura) como Prosperidad, Vicálvaro, Móstoles, Alcorcón, o Talamanca del Jarama, entre otros.

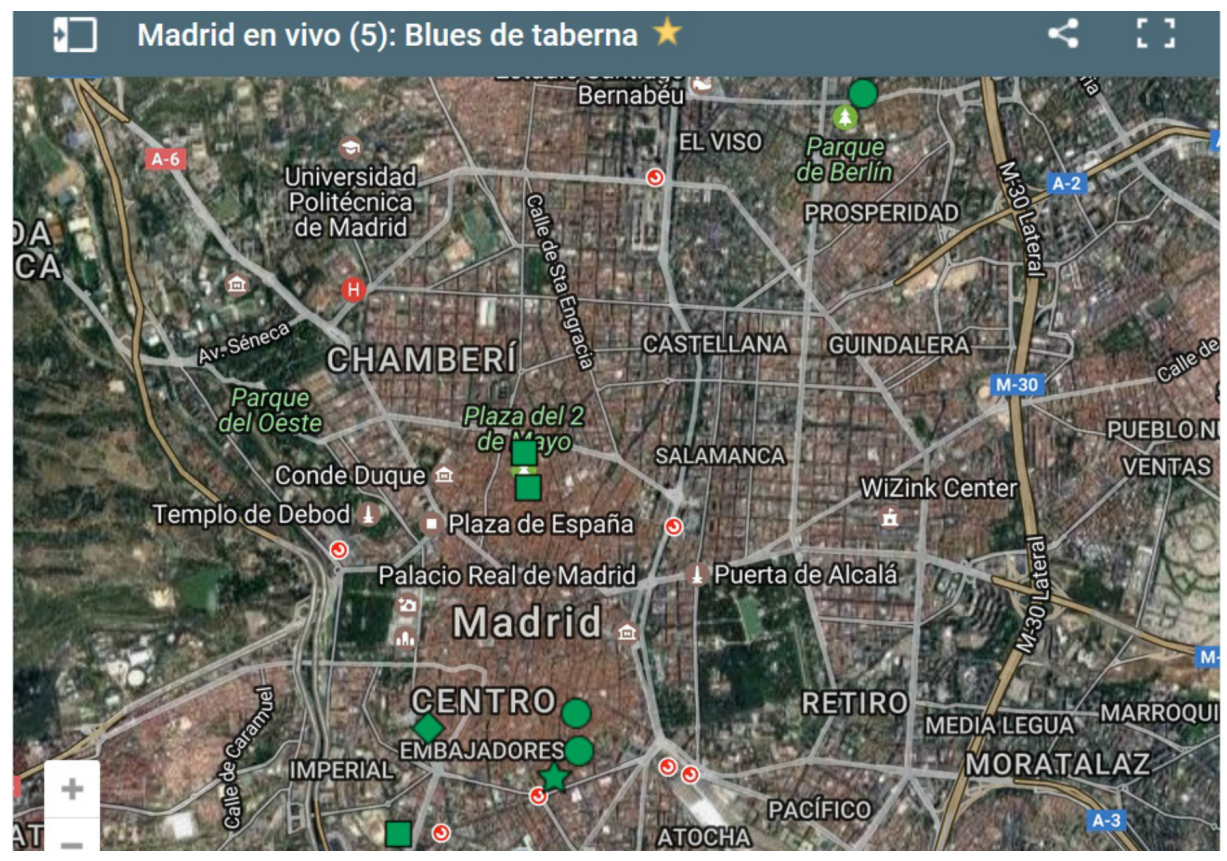

En primer lugar, cabe destacar la importancia de la Taberna Alabanda (2010), marcada con una estrella en el barrio de Lavapiés, porque constituye en cierta medida la sede de la Sociedad de Blues de Madrid y de muchas de sus actividades, principalmente los conciertos-jam de los domingos. Por ello, Alabanda se ha convertido en un lugar de reunión para aficionados y músicos de la escena, que participan periódicamente en los eventos musicales celebrados. Además, podemos mencionar el caso de la Bodega del Águila (2012), marcada con un rombo en la zona de La Latina. Esta pequeña bodega cuenta con un público asiduo, que disfruta de la música y del ambiente popular. Sin escenario per se, las actuaciones se caracterizan por el sonido generalmente acústico, sin amplificación y, en el caso del blues (que convive con el jazz tradicional y el pop-rock) destaca la interpretación de blues rural. 


\subsection{Madrid en vivo desde la escena de blues}

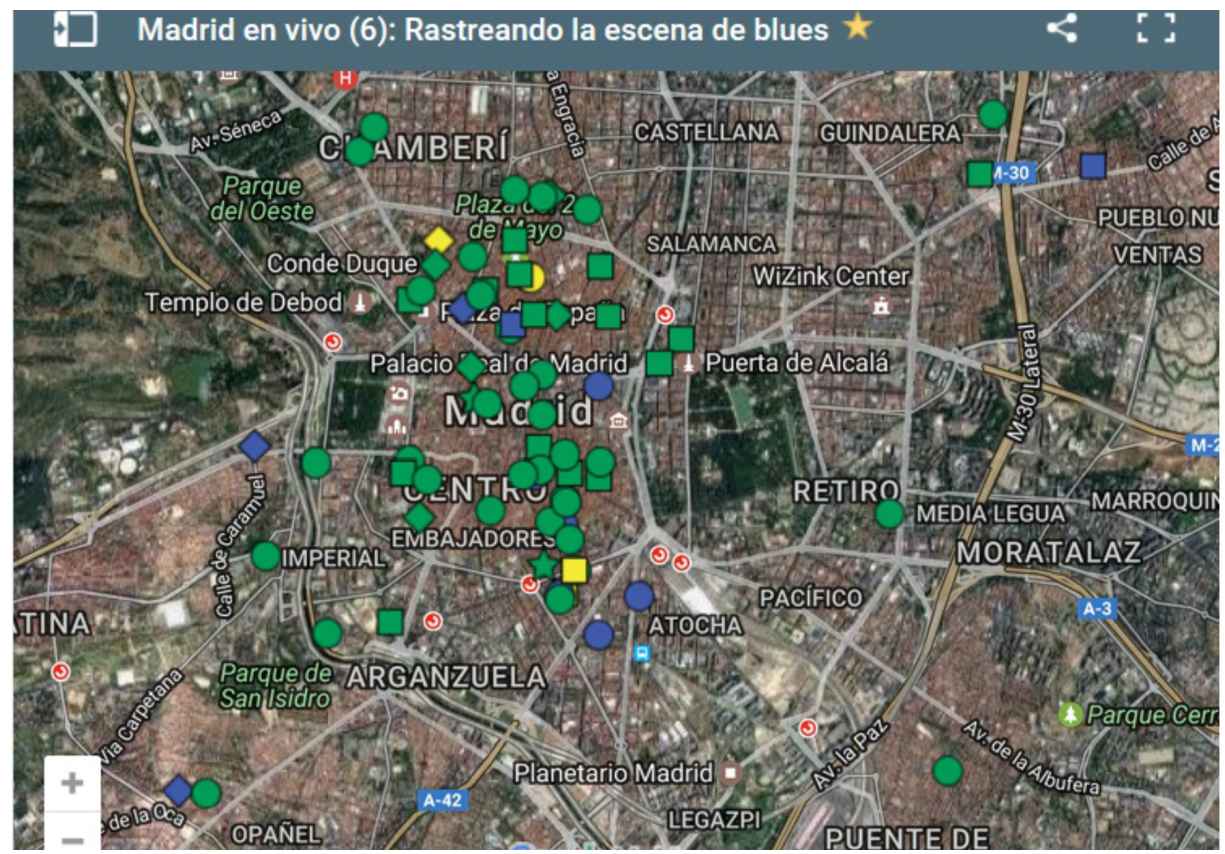

Por último, presentamos el mapa final ("Rastreando la escena de blues") con todos los lugares de interacción musical activos de cada categoría y mapa previo. Hay un total de 97 lugares, incluyendo 11 festivales. La gran mayoría están situados en la distrito centro -acotado entre Embajadores (al sur) y Universidad (al norte). Además, se aprecian extensiones en los alrededores del centro, sobre todo en la zona sur (especialmente sur oeste) y también, aunque en menor medida, en la zona norte. Esta localización y organización de la escena sobre el espacio urbano madrileño está en consonancia con el monocentrismo y la alta densidad poblacional de Madrid (Roca, Arellano y Moix, 2011), con un modelo de organización concéntrica en cuyo interior hay un potente núcleo sobre el que gravita la ciudad, y también con la constante celebración de eventos musicales y artísticos.

Si nos fijamos en las ausencias -en la actual inactividad de locales de música en vivo que han sido relevantes históricamente-, se aprecia que cierre acumulativo de lugares de interacción ha sido especialmente significativo tanto en el centro (como cabría esperar por el notable dinamismo de estas zonas en las capitales) como en la zona este. En este sentido, la ausencia de clubs relacionados con el blues y la música en vivo en el este de Madrid contrasta con la mayor presencia previa de lugares de interacción musical en barrios y distritos de este área, como Vallecas (Cotton Blues, 1991-1994), Retiro (Vapor Blues, 1997-2001), Pueblo Nuevo (Beethoven Blues Bar, 1996-2011), y Salamanca (Teatro Salamanca, 1935-1987; Teatro Carlos III, 19522007; Whisky Jazz, 1959-1971; Sala Mónaco, 1964-1966; Balboa, 1973-c.1981; Sala Universal, 1986-1989), entre otros.

Si bien cada lugar de interacción musical tiene su propia historia y sus particularidades, el cierre de locales situados más allá de los límites del centro responde 
generalmente a una conjunción de factores, entre los que destacan: la acumulación de dificultades económicas debido a los múltiples gastos $\mathrm{y}$, en menor medida, al descenso de públicos; el impacto de las transformaciones del barrio y las presiones restrictivas de (algunos) vecinos e instituciones; y la tensión generada entre la actividad nocturna y las crecientes responsabilidades de la vida adulta y familiar. ${ }^{9}$

\section{Conclusiones}

Tras presentar esta serie de cartografías musicales de la escena madrileña desde la perspectiva del blues, cabe destacar la notable presencia y extensión de la música blues en la escena urbana y, al mismo tiempo, su integración en lugares de música en vivo que no están específicamente dedicados a ello, sino que se identifican con distintos géneros -incluyendo el jazz, el soul y el funk, el pop-rock y el flamenco, entre otros. De este modo, confirmamos que los mapas representan y, al mismo tiempo, trascienden la escena de blues en Madrid, evidenciando el solapamiento y la potencial interrelación de distintos géneros musicales en lugares comunes de la escena urbana.

En consonancia con los planteamientos sociológicos sobre los "mundos del arte", las distintas escenas musicales que conviven en Madrid-definidas generalmente por género o subgénero (escena de blues, escena de jazz, escena de soul/funk, escena de rock, etc.)- tienen "relaciones cercanas y extensas con los mundos de los que tratan de distinguirse. Comparten fuentes de abastecimiento con otros mundos [musicales y culturales], reclutan personal de ellos, y compiten con ellos por el público y el apoyo financiero" (Becker, 2008: 36). Debido a la semejanza de sus prácticas y discursos sociales -así como a los vínculos desarrollados entre participantes de unas y otras (sub)escenas-, la diversidad musical, territorial e identitaria de las distintas (sub)escenas (o semiosferas) que conviven en Madrid constituye un universo común cuantitativamente superior, fragmentado y desigual en su interior, pero fundamentalmente unitario si se observa desde una perspectiva macro.

Las cartografías musicales de la escena musical madrileña contienen una gran cantidad de información sobre ella, así como sobre la historia y la memoria musical y cultural de la ciudad. En términos cuantitativos, la siguiente tabla muestra un resumen del número de lugares de interacción contabilizados en cada categoría-mapa; un total de 147 lugares.

\begin{tabular}{|c|c|c|c|c|c|c|}
\hline \multicolumn{7}{|c|}{ Datos de las cartografías musicales } \\
\hline & $\begin{array}{c}\text { Lugares } \\
\text { de blues }\end{array}$ & $\begin{array}{c}\text { Lugares de jazz } \\
\text { y blues }\end{array}$ & $\begin{array}{c}\text { Lugares } \\
\text { de soul/ } \\
\text { funk }\end{array}$ & $\begin{array}{c}\text { Varios } \\
\text { géneros }\end{array}$ & $\begin{array}{c}\text { Blues de } \\
\text { taberna }\end{array}$ & N $^{\text {o total }}$ \\
\hline Activos & 7 & 11 & 9 & 55 & 17 & 99 \\
\hline Inactivos & 11 & 8 & 3 & 25 & 1 & 48 \\
\hline Total & 18 & 17 & 12 & 80 & 18 & 147 \\
\hline
\end{tabular}

9 David Menor (propietario del Vapor Blues) se refirió a "problemas con la comunidad y la junta municipal de Retiro"-que condujeron a la supresión de la música en directo que ofrecía; a la escasa rentabilidad de la economía de la música en vivo; y a "la incompatibilidad de este tipo de local con la vida familiar (elegí escuchar buen blues en casa al lado de mi mujer e hija)". 
En términos cualitativos, estas cartografías ofrecen una contextualización espaciotemporal de la escena musical madrileña a través de la representación cartográfica digital. La enorme riqueza que proporcionan los datos sobre los lugares de interacción mapeados (nombre, localización, fechas de actividad, tipología, actuaciones destacadas, etc.) hace que la traducción de su contenido a la escritura de investigación académica difícilmente pueda producirse de un modo completo en una sola operación, en un solo texto, o en un solo trazo.

Las siguientes tablas, basadas en los datos cualitativos de los lugares de interacción musical (activos e inactivos, respectivamente), sirven para ilustrar la complejidad que conlleva la producción cartográfica de una escena musical como la de Madrid, y apunta hacia una multiplicidad inabarcable de historias particulares sobre los propios lugares y sobre su relación con los participantes de la escena (músicos, aficionados, periodistas alternativos, etc.).

\begin{tabular}{|c|c|c|c|c|}
\hline \multicolumn{5}{|c|}{ Lugares de interacción musical activos } \\
\hline $\begin{array}{l}\text { Lugares de } \\
\text { blues }\end{array}$ & $\begin{array}{l}\text { Lugares de } \\
\text { jazz y blues }\end{array}$ & $\begin{array}{l}\text { Lugares de } \\
\text { soul/funk }\end{array}$ & Varios géneros & $\begin{array}{l}\text { Blues de } \\
\text { taberna }\end{array}$ \\
\hline $\begin{array}{l}\text { La Coquette } \\
\text { (1984); En- } \\
\text { fase Estudio } \\
\text { (1999); } \\
\text { Blues Oscuro } \\
\text { Casi Negro } \\
\text { (2012); } \\
\text { Escuela de } \\
\text { Blues de Ma- } \\
\text { drid (2011); } \\
\text { Festival de } \\
\text { Blues de } \\
\text { Los Santos } \\
\text { (2012); Al- } \\
\text { batros Blues } \\
\text { Festival } \\
\text { (2013); Le- } \\
\text { ganés Blues } \\
\text { Festival } \\
\text { "South Side" } \\
\text { (2015) }\end{array}$ & $\begin{array}{l}\text { El Desper- } \\
\text { tar (1981); } \\
\text { Clamores } \\
\text { Jazz (1981); } \\
\text { Café Central } \\
\text { (1982); } \\
\text { Contrapunto } \\
\text { Jazz Café } \\
\text { (1998); El Pla- } \\
\text { za Jazz Club } \\
\text { (2000); Bogui } \\
\text { Jazz (2005); } \\
\text { Recoletos Jazz } \\
\text { Club (2007); } \\
\text { Big Mama } \\
\text { Swing (2012); } \\
\text { Swing Ma- } \\
\text { niacs (2014) } \\
\text { Festival de } \\
\text { Jazz en Ma- } \\
\text { drid (1961); } \\
\text { Festival de } \\
\text { Jazz de Boadi- } \\
\text { lla del Monte } \\
\text { (c.1999) }\end{array}$ & $\begin{array}{l}\text { MOE Club } \\
\text { (1998); } \\
\text { Tempo Club } \\
\text { (2002); } \\
\text { Marula Café } \\
\text { (2002); } \\
\text { El Junco } \\
\text { (2004); } \\
\text { Intruso Bar } \\
\text { (2011); The } \\
\text { Maderfaker } \\
\text { (1996); La } \\
\text { Huelga de } \\
\text { Lavapiés } \\
\text { (2010); Fes- } \\
\text { tival Madrid } \\
\text { es Negro } \\
\text { (2010); } \\
\text { Black is } \\
\text { Black Soul } \\
\text { Party (2012) }\end{array}$ & $\begin{array}{l}\text { Círculo de Bellas Artes (1880); Teatro } \\
\text { Lara (1880/1994); Teatro Monumental } \\
\text { (1923); Teatro Pavón (1925); Plaza de } \\
\text { Toros de las Ventas (1934); Leturiaga } \\
\text { (1963); Sala La Riviera (1964); Estadio } \\
\text { Vicente Calderón (1966); La Fídula } \\
\text { (1978); Sala Sol (1979); Sala Hebe } \\
\text { (1980); Joy Eslava (1981); Tablada } 25 \\
\text { (1981); Casa Patas (1985); Onda Latina } \\
\text { (1986); Teatro Nuevo Apolo (1987); } \\
\text { Honky Tonk (1987); Radio Carcoma } \\
\text { (1988); Sala Siroco (1989); Sala Cara- } \\
\text { col (1991); Bar Palermo (1992); Moby } \\
\text { Dick (1992); Sala Aqualung (1992); } \\
\text { Irish Rover (1995); Barracudas (1997); } \\
\text { Sala Marco Aldany (1998); Gruta 77 } \\
\text { (2000); La Noche En Vivo (2001); Sala } \\
\text { ContraClub (2003); Sala Barco (2004); } \\
\text { Legend (2006); Teatro Circo Price } \\
\text { (2007); JazzVille (2007); Fun House } \\
\text { (c.2009); Café Berlín (2011/2016); } \\
\text { Mercado de Moncloa (2013); Collage } \\
\text { Drinks \& Arts (2014); Delia Records } \\
\text { (2014); El 14 (2014); El Pez Eléctrico } \\
\text { Rock Bar (2014); Café Barbieri (2015); } \\
\text { Rompeolas Locales (2015); Blackbird } \\
\text { Rock Bar (2016); Sala Boite; The Old } \\
\text { Blues Bar; Fender Club; Sala Penélope; } \\
\text { Sensorama Jazz Café; La Fontana de } \\
\text { Oro; James Joyce Irish Pub Madrid; } \\
\text { Dando la nota; F. Veranos de la Villa; F. } \\
\text { Cultura Inquieta (2012); F. Madgarden } \\
\text { (2014); F. Mad Cool (2016) }\end{array}$ & $\begin{array}{l}\text { Albatros Tex } \\
\text { Mex (1984); } \\
\text { Kiosko Re- } \\
\text { creativo de } \\
\text { Talamanca del } \\
\text { Jarama (2004); } \\
\text { Café del Infante } \\
\text { (2005); El Gato } \\
\text { Verde (2008); } \\
\text { Pirata's Rock } \\
\text { Wey (c.2009); } \\
\text { Taberna Alaban- } \\
\text { da (2010); Bo- } \\
\text { dega del Águila } \\
\text { (2012); Heaven's } \\
\text { Door Móstoles } \\
\text { Abbey (2012); } \\
\text { Dakota Custom } \\
\text { Bar (2013); } \\
\text { Restaurante } \\
\text { Ezaro (c.2013); } \\
\text { Deltoya Music } \\
\text { Bar (2014); } \\
\text { Restaurante } \\
\text { Alfolí de la Sal; } \\
\text { Obsoleto Bar; } \\
\text { Café de Ruiz; } \\
\text { Restaurante San } \\
\text { Telmo; Cafetería } \\
\text { Lima; La Funda } \\
\text { Mental }\end{array}$ \\
\hline
\end{tabular}




\begin{tabular}{|c|c|c|c|c|}
\hline \multicolumn{5}{|c|}{ Lugares de interacción musical inactivos } \\
\hline Lugares de blues & $\begin{array}{l}\text { Lugares de } \\
\text { jazz y blues }\end{array}$ & $\begin{array}{l}\text { Lugares de } \\
\text { soul/funk }\end{array}$ & Varios géneros & $\begin{array}{c}\text { Blues de } \\
\text { taberna }\end{array}$ \\
\hline $\begin{array}{l}\text { Cotton Blues (1991- } \\
\text { 1994); Vapor Blues } \\
\text { (1997-2001); Beetho- } \\
\text { ven Blues Bar (1996- } \\
\text { 2011); Habitación 101 } \\
\text { - Juke-joint Fuencarral } \\
\text { (2014-2016); Downtown } \\
\text { (c.1993-2000); Madrid } \\
\text { Rock 'n' Blues Festival } \\
\text { (2012); I Festival de } \\
\text { Blues de la Escuela de } \\
\text { Blues de Madrid (2012); } \\
\text { Blues, Beers \& Bikers } \\
\text { (2012); I Festival de } \\
\text { Blues y Rock de Daganzo } \\
\text { (2012); I Festival de } \\
\text { Blues de El Intruso; } \\
\text { Butarque Blues Festival } \\
\text { (2015) }\end{array}$ & $\begin{array}{l}\text { Whisky Jazz I } \\
(1959-1971) ; \\
\text { Whisky Jazz II } \\
\text { (1971-1995); } \\
\text { Balboa Jazz } \\
\text { (1973-c.1981); } \\
\text { Café Populart } \\
\text { (1988-2016); } \\
\text { Segundo Jazz } \\
\text { (1988-2016); } \\
\text { Orient Express } \\
\text { (años 1990); } \\
\text { FonJazz Club } \\
\text { (2014); Festival } \\
\text { de Jazz La Es- } \\
\text { calera De Jacob } \\
\text { (2009-2013) }\end{array}$ & $\begin{array}{l}\text { Soul Station } \\
\text { (2009-2013); } \\
\text { Club Kath- } \\
\text { mandú; Moe } \\
\text { Black Music } \\
\text { Festival } \\
(2006-2012)\end{array}$ & $\begin{array}{l}\text { Teatro Circo Price (1880- } \\
\text { 1970); Teatro Novedades } \\
\text { (1857-1928); Cine Royal- } \\
\text { ty (1914-c.1960); Florida } \\
\text { Dancing (1920s-1930s). } \\
\text { Cine Avenida (1928- } \\
\text { 2009); Teatro Gran } \\
\text { Metropolitano (1930- } \\
\text { c.1965); Teatro Salamanca } \\
\text { (1935-1987); Teatro Al- } \\
\text { béniz (1945-2009); Teatro } \\
\text { Carlos III (1952-2007); } \\
\text { Sala Mónaco; Paladium } \\
\text { de Cristal; Colegio Mayor } \\
\text { Universitario San Juan } \\
\text { Evangelista; Discoteca La } \\
\text { Argentina (1971-1990s); } \\
\text { Sala M\&M (1970s-); } \\
\text { Rock-Ola (1981-1985); } \\
\text { Sala Canciller (1983- } \\
\text { 1995). Agapo (1985- } \\
\text { 1991); Sala Universal } \\
\text { (1986-1989) Sala Jácara } \\
\text { (1986-1991); Jazz Madrid } \\
\text { (1980s-1990s); Revolver } \\
\text { Club (1991). Discoteca } \\
\text { Die Mauer (1992-1995); } \\
\text { Kenny Bell (1995-1996); } \\
\text { La Boca Club (1999- } \\
\text { 2015). Estadio Román } \\
\text { Valero (Campo }\end{array}$ & $\begin{array}{l}\text { Hell Paso } \\
\text { Custom } \\
\text { Bar (2013- } \\
2016)\end{array}$ \\
\hline
\end{tabular}

Por una parte, la producción y publicación de estas cartografías musicales constituye la consolidación de una base de datos - de un depósito de conocimiento sobre la dimensión material y espacio-temporal de la escena, que debe ser actualizado según su devenir. Por otra, supone un punto de partida para explorar nuevos caminos y líneas de investigación. En este sentido, los datos sobre los lugares cartografiados en la escena musical madrileña nos invitan a plantearnos preguntas sobre distintos aspectos de la apropiación histórica de la música estadounidense y afroamericana en Madrid, así como sobre la construcción histórica de una escena musical propia y sobre las procesos de hibridación desarrollados en el contexto de los locales de música en vivo.

En primer lugar, desde la perspectiva actual de mi investigación, cabría pensar en la aplicación de las cartografías a una conceptualización histórica de las escenas estudiadas, entendiendo que éstas se construyen colectivamente en distintas fases, definidas en relación con el contexto musical, sociocultural y político en el que es- 
tán situadas. Además, el intrínseco vínculo entre los locales de música en vivo y las actuaciones -muchas de ellas históricas- que se han producido en ellos hace que nos preguntemos, por ejemplo: ¿Qué hay hoy en el espacio en el que estuvo el Club Mónaco (Calle Fundadores, 9; 1964-1966) -"la sala selecta del barrio de Salamanca" que acogió la actuación del popular grupo británico The Animals en 1965? ¿Y en antiguo Teatro-Cine Salamanca (C/Conde Peñalver, 8; 1935-1987), donde actuó el legendario músico afroamericano Ray Charles en $1971 ?^{10}$ La cartografía musical nos permite responder que en el sitio del Club Mónaco hay hoy un solar vacío, donde recientemente han comenzado unas obras, y en el edificio del Teatro Salamanca -un exponente de la arquitectura racionalista- hay una tienda de la cadena de moda holandesa C\&A. Junto a otros casos, como las experiencias de propietarios de locales actualmente inactivos, estos ejemplos sobre la evolución de ciertos lugares de interacción musical de referencia resultan significativos porque apuntan hacia una serie de cambios en la cultura urbana contemporánea, que tienden a relacionarse con cierta pérdida del valor y la importancia social de la música en directo -especialmente en su concepción como práctica cotidiana.

En definitiva, entendemos que esta presentación de las cartografías musicales de la escena musical madrileña y la alusión a algunas de sus potenciales vías de desarrollo investigador proporcionan una eficiente representación visual de la escena, que permite a cualquier lector reconocerla y participar en ella (online y offline), que conecta cuestiones musicales con transformaciones urbanas y socioculturales, y que da herramientas para desarrollar nuevas reflexiones y análisis sobre la ciudad, la música popular y las nuevas tecnologías digitales.

\section{Bibliografía}

Barrionuevo, A. (2016), Club de Reyes. Madrid: Pocket Rocket Films.

Becker, H. (2008), Art Worlds. Berkeley: University of California Press.

Blacking, J. (1995), How Musical is Man? Washington: University of Washington Press.

De-Sousa Santos, B. (1991), "Una cartografía simbólica de las representaciones sociales: Prolegómenos a una concepción posmoderna del derecho", Nueva Sociedad, n. 116, noviembre-diciembre, pp. 18-38.

Domínguez, S. (2002), Bienvenido Mr. Rock... Los Primeros Grupos Hispanos 1957-1975. Madrid: Fundación Autor-SGAE.

Eco, U. (1986), “¿El público perjudica a la televisión?”, en Miguel de Moragas (ed.): Sociología de la Cultura de Masas. II. Estructura, funciones y efectos. Barcelona: Gustavo Gili.

Finn, J. y Lukinbeal, C. (2009), "Musical Cartographies: Los Ritmos de los Barrios de la Habana", en Johansson, O. y Bell, T. L. (eds.), Sound, Society and the Geography of Popular Music. Surrey: Ashgate.

Grazian, D. (2003), Blue Chicago. The Search for Authenticity. Chicago: The University of Chicago Press.

10 La actuación de The Animals ha sido narrada por Salvador Domínguez (2002) y la de Ray Charles ha sido destacada por la Sociedad de Blues de Madrid (2012), que en su web comparte el cartel del evento. La información sobre el Club Mónaco (dirección, periodo de actividad y eslogan) ha sido consultada en la hemeroteca del periódico ABC, donde la sala se anunció continuadamente entre 1964 y 1966. 
Lashua, B., Cohen, S., y Schofield, J. (2010), "Popular music, mapping, and the characterization of Liverpool", Popular Music History, 4.2., pp. 126-144.

Malinowski, B. (1986), Los argonautas del Pacifico occidental I. Barcelona: Planeta-De Agostini.

Manovich, L. (2005), El lenguaje de los nuevos medios de comunicación. Barcelona: Paidós.

Marcus, G. (1995), "Ethnography in/of the World System: The Emergence of Multi-Sited Ethnography”, Annual Review of Anthropology, Vol. 24, pp. 95-117.

Martín-Barbero, J. (2002), El oficio del cartógrafo. Travesías latinoamericanas de la comunicación a la cultura. Mexico, D.F.: Fondo de Cultura Económica.

Nettl, B. (1960), "Musical Cartography and the Distribution of Music", Southwestern Journal of Anthropology, Vol. 16, No. 3, pp. 338-347.

O’Meara, C.P. y Tretter, E. (2013): "Sounding Austin: Live Music, Race, and the Selling of a City", en Holt, F. y Wergin, C. (eds.), Musical Performance in the Changing City. New York: Routledge.

Pedro, J. (2015), "Madrid en vivo: Rastreando la escena de blues", Blues Vibe, 22 de septiembre. https://bluesvibe.com/2015/09/22/madrid-en-vivo-rastreando-la-escena-de-bluesen-madrid/ [Consulta: 02/02/2017]

Roberts, L. (ed.) (2012), Mapping Cultures. Place, Practice, Performance. Basingstoke: Palgrave McMillan.

Roca, J., Arellano, B., y Moix, M. (2011), "Estructura urbana, policentrismo y sprawl: los ejemplos de Madrid y Barcelona", Ciudad y Territorio. Estudios Territoriales, vol. XLIII (168), pp. 299-321.

Santos, E. (2015), "Madrid, a través de las canciones que mencionan sus rincones (MAPA INTERACTIVO)", Huffington Post, 15 de mayo. http://www.huffingtonpost.es/2015/05/15/ canciones-madrid-mapa_n_7214408.html [Consulta: 13/02/2017]

Shank, B. (1994), Dissonant Identities: The Rock 'n'Roll Scene in Austin, Texas. New

England: Wesleyan University Press.

Sociedad de Blues de Madrid (2012), "Historia", Sociedad de Blues de Madrid. http://www. sociedaddebluesdemadrid.com/blues-en-madrid/ [Consulta: 08/02/2017]

Tretter, E. (2012), “Austin Restricted: Progressivism, Zoning, Private Racial Covenants, and the Making of a Segregated City", Report Submitted to the Institute for Urban Policy Research Analysis. 